Supplement of Saf. Nucl. Waste Disposal, 1, 143-144, 2021

https://doi.org/10.5194/sand-1-143-2021-supplement

(C) Author(s) 2021. CC BY 4.0 License.

Supplement of

\title{
Dissolution of simplified nuclear waste glass and formation of secondary phases
}

\section{Felix Brandt et al.}

Correspondence to: Felix Brandt (f.brandt@ fz-juelich.de)

The copyright of individual parts of the supplement might differ from the article licence. 


\section{Dissolution of simplified nuclear waste glass (ISG) and formation of secondary phases}

Felix Brandt' ${ }^{1}$, Martina Klinkenberg ${ }^{1}$, Sébastien Caes ${ }^{2}$, Jenna Poonoosamy ${ }^{1}$, Wouter Van Renterghem ${ }^{3}$, Juri Barthel ${ }^{4}$, Karel Lemmens², Dirk Bosbach ${ }^{1}$, Karine Ferrand ${ }^{2}$ 1'Institute of Energy and Climate Research (IEK-6), Nuclear Waste Management and Reactor Safety, Forschungszentrum Jülich GmbH, 52425 Jülich, Germany; f.brandt@ftz-juelich.de

4Ernst Ruska-Centre (ER-C 2), Forschungszentrum Jülich GmbH, 52425 Jülich, Germany

\section{Introduction \& Objectives:}

Leaching mechanism $=$ selective removal of cations

Still state-of-the art for waste management agencies but under debate in the scientific community

Stages

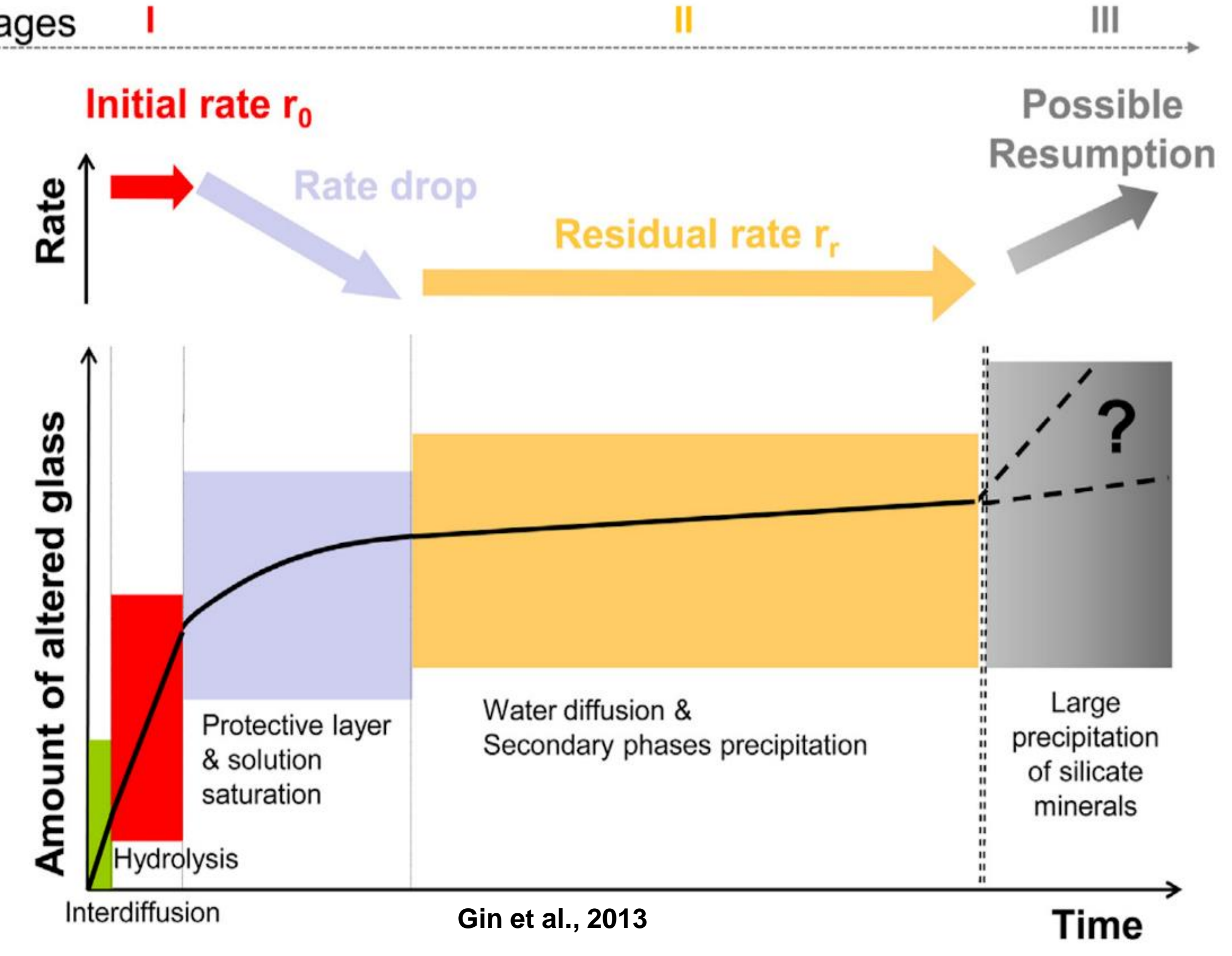

Models based on the proposed leaching mechanism are mainly based on macroscopic experiments at low surface area to volume (SA/V) ratio (e.g. Frugier et al., 2018)

- Details of surface alteration layer (SAL) formation? - Formation of new phases and incorporation of RN? - Relevant experimental conditions e.g. high $\mathrm{pH}$, low due to the presence of concrete and cement?

\section{$\rightarrow$ The microscopic view}

Effect of high pH

Morphology and properties of altered phase? - Type of newly formed secondary phases?

Lower temperature

- More difficult to form crystalline secondary phases? - Slower dissolution of the glass?

Higher SA/V

- More secondary phase formation?

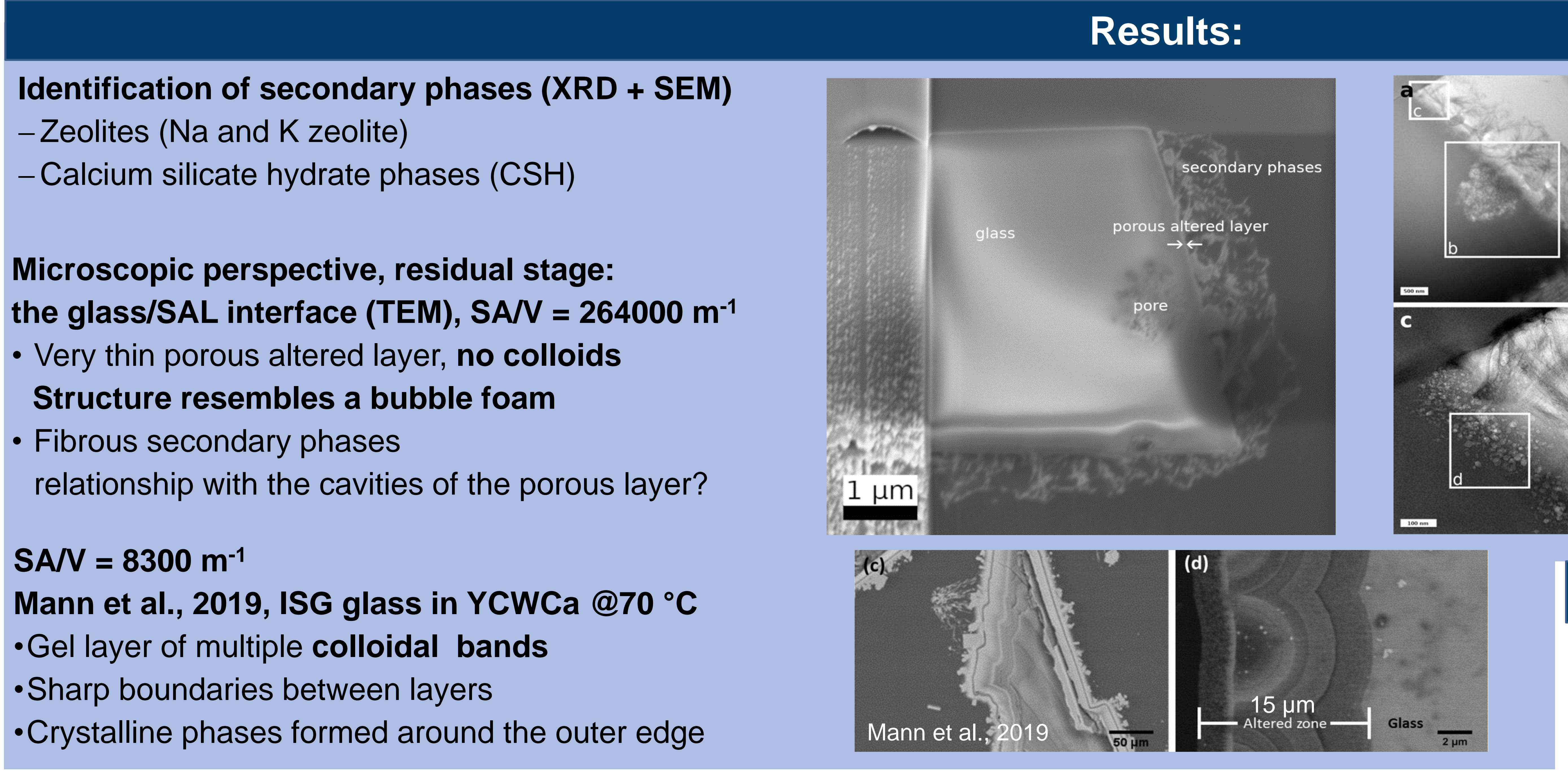

Macroscopic perspective

Normalized element release $\mathrm{NL}_{i}=$ amount of glass $\left(\mathrm{g} / \mathrm{m}^{2}\right)$ dissolved at a given time calculated from the

mass balance of dissolved elements $\left(\mathrm{NL}_{\mathrm{i}}\right)$
Blind prediction: All cations released end up in

element release. $\mathrm{NL}_{\mathrm{i}}$ and residual rateof $6 \times 10^{-6} \mathrm{~g} / \mathrm{m}^{2} \mathrm{~d}$ secondary phases, if they are supersaturated

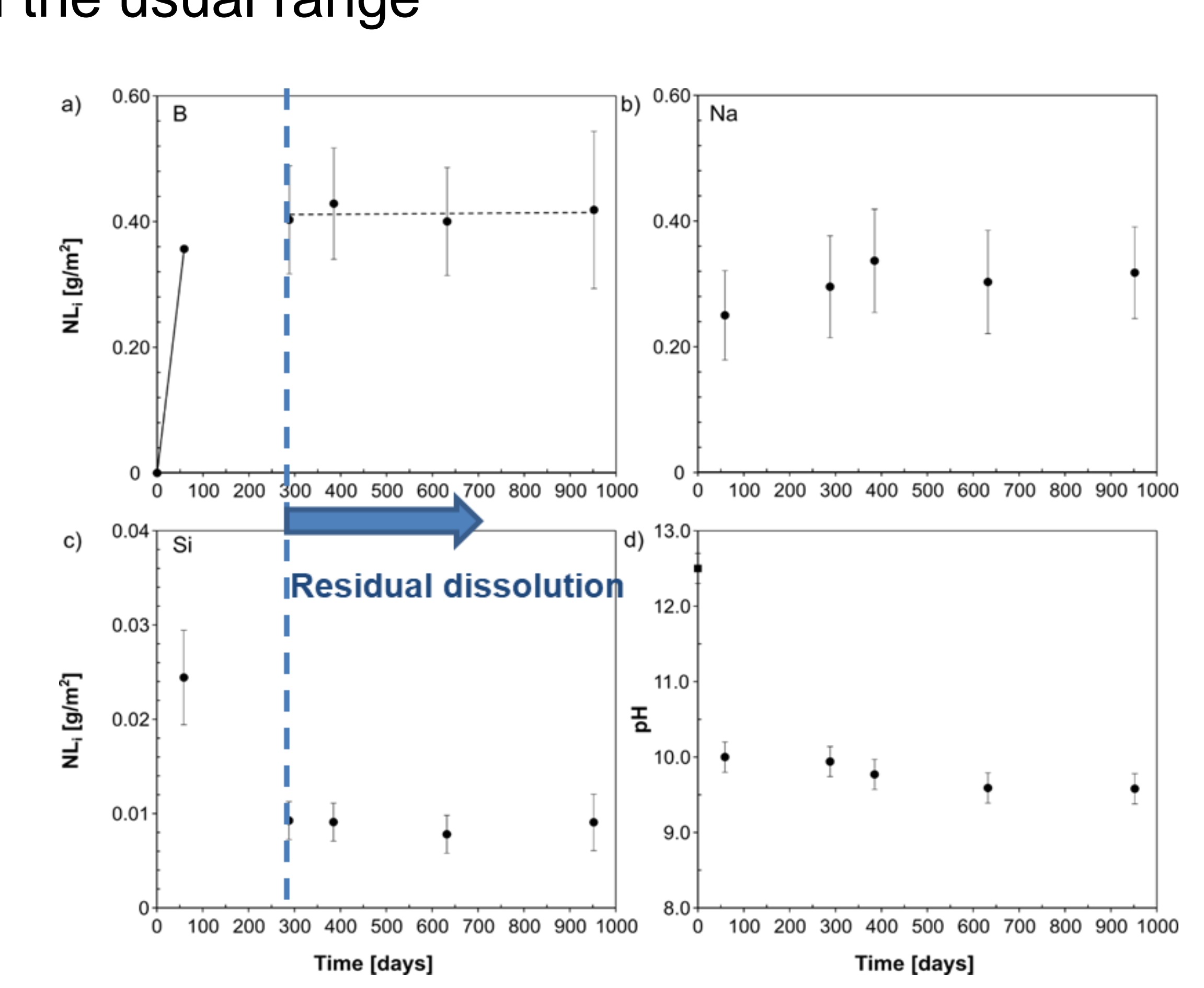

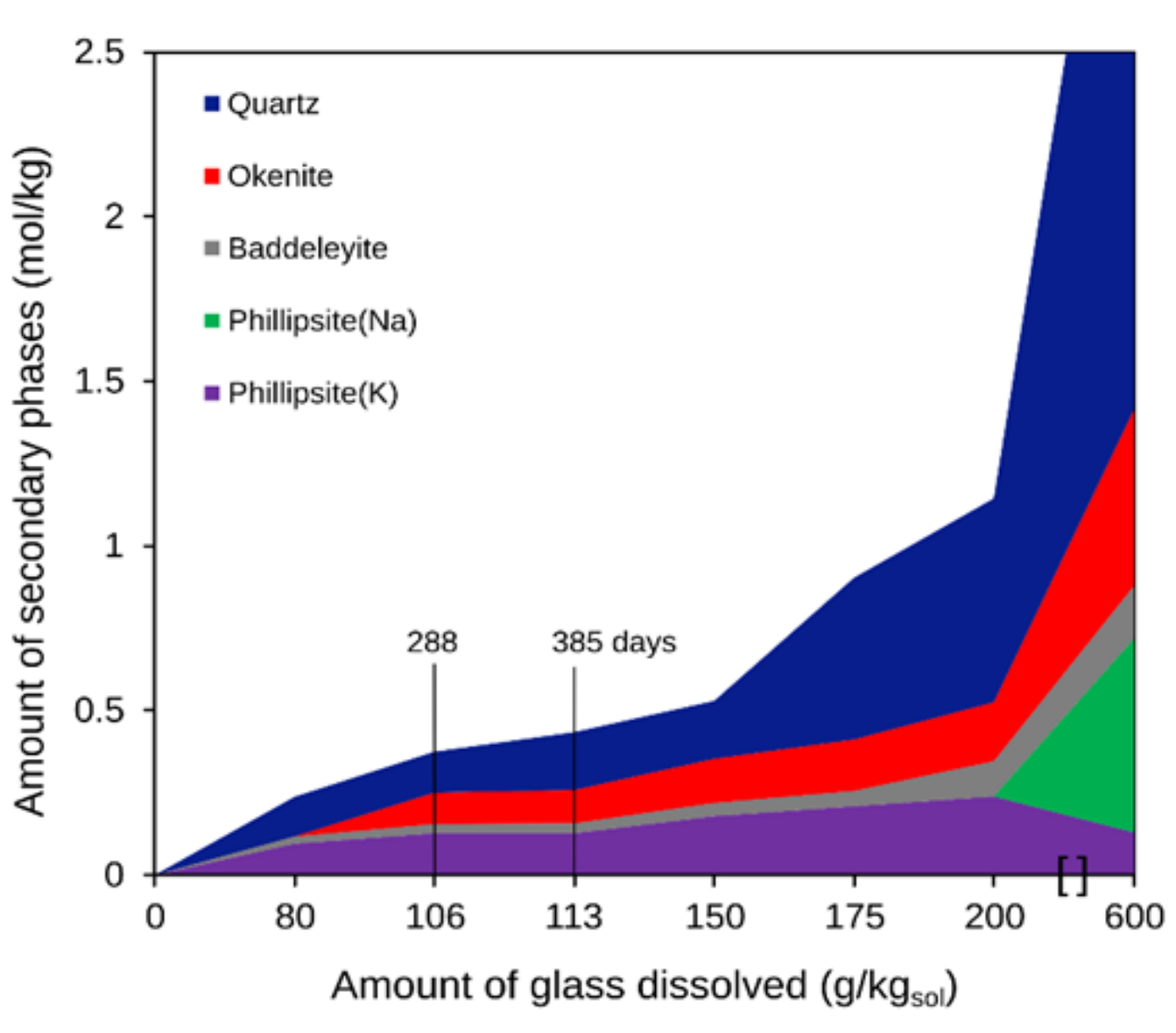

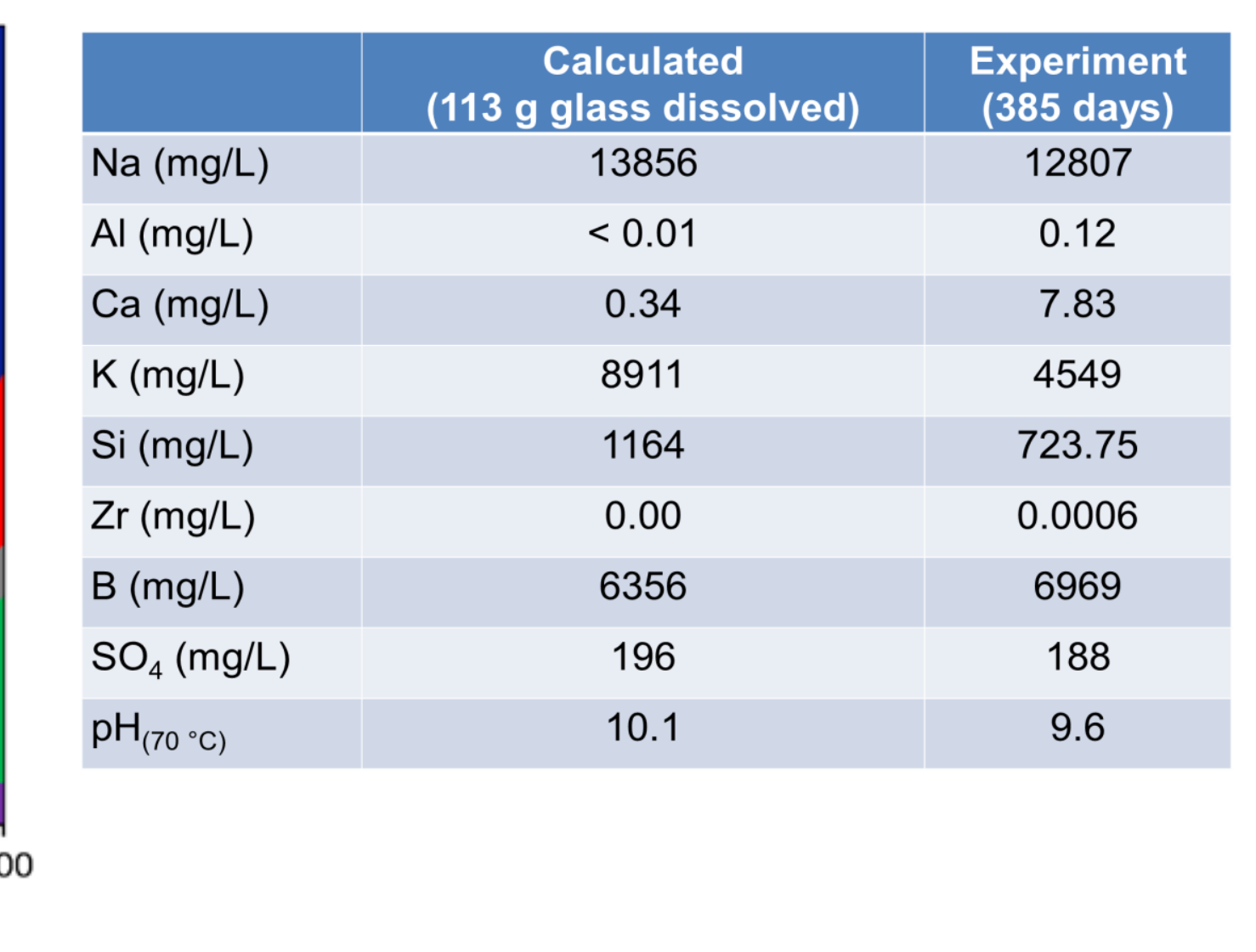
- Zeolite - $\mathrm{CSH}$ (Okenite)
Predicted and observed Not observed due to kinetics

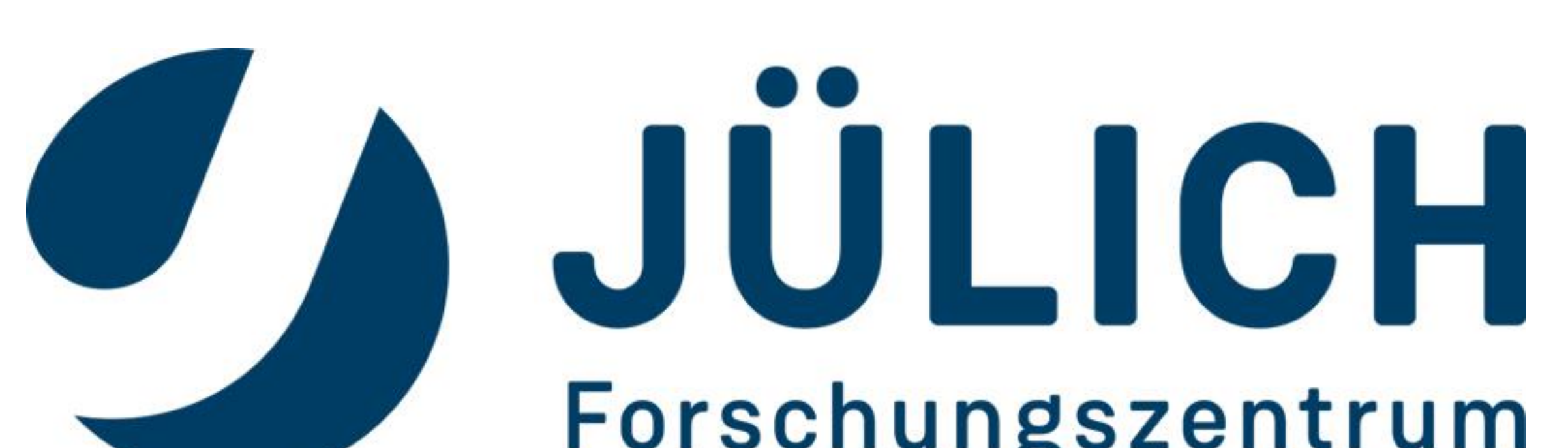

Forschungszentrum

\section{YCWCa}

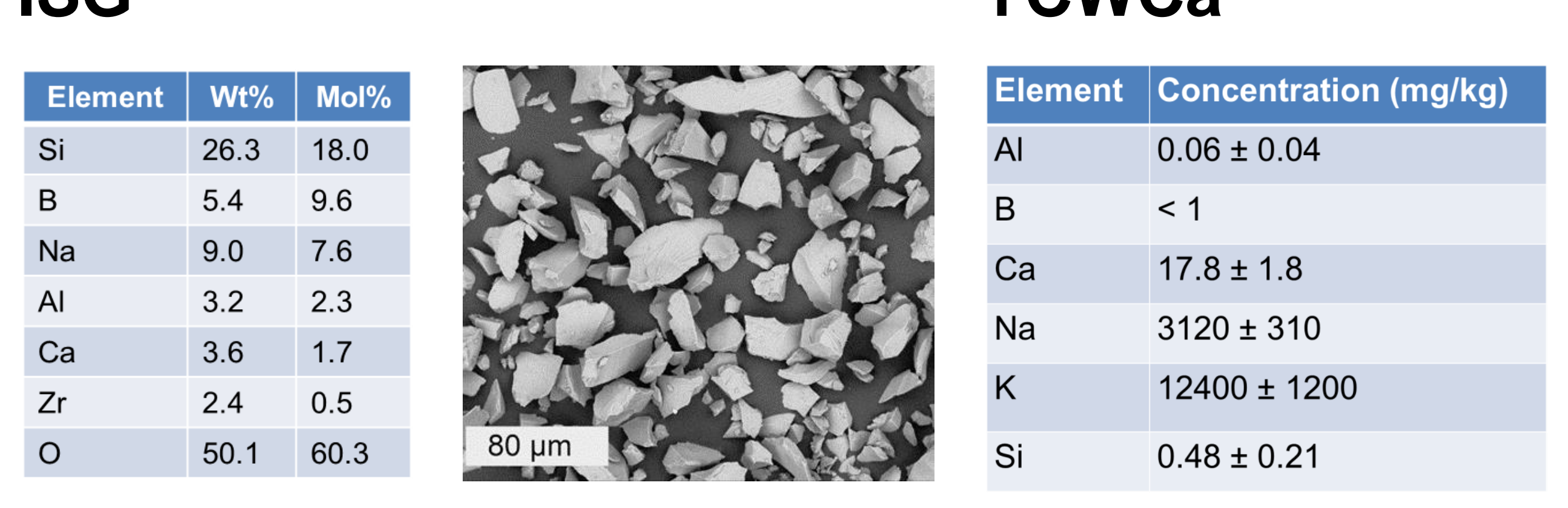

Materials and Methods:

Batch experiments at high $\mathrm{pH}$ and high $\mathrm{SA} / \mathrm{V}$

Modelling of thermodynamic equilibria (GEMS-PSI) Sample taken from day 385

-Estimation of secondary phase equilibrium assuming - Sample embedded in resin

congruent dissolution and precipitation $\quad$ Polished to obtain a cross-section

Characterization of the solid

Separation of crystalline secondary phases

- FIB section prepared perpendicular to the polished surface

XRD of separated grain size fractions

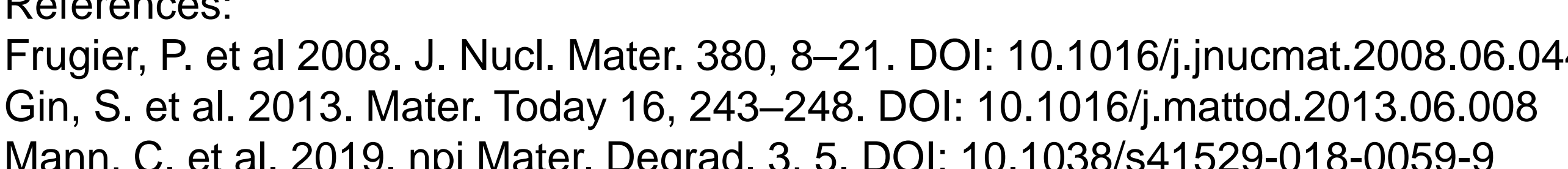

